\title{
A ESTÉTICA DE MIKEL DUFRENNE
}

Roberto Figurelli:

SINTESE - O texto delineia a relação entre a produção teórica sobre a estética de M. Dufrenne e a herança fenomenológica husserliana, a partir de um estudo da estrutura da Phénoménologie de l'expérience esthétique.

PALAVRAS-CHAVE - Estética. Fenomenologia. Mikel Dufrenne. Husserl.
ABSTRACT - This article outlines the relationship between the theoretical production on $\mathrm{M}$. Dufrennes's aesthetics and Husserl's phenomenological legacy, starting from a study of the Phénoménologie de l'Expénience esthétique.

KEY WORDS - Aesthetics. M. Dufrenne. Husserl. Phenomenology.

Em 1953, Mikel Dufrenne (1910-1995) lançou a Fenomenologia da experiência estética (Phénoménologie de l'expérience esthétique). A publicação dessa obra assinala o término da década de ouro da fase francesa da fenomenologia. Iniciada em 1943, sob o impacto de O ser e o nada (L'être et le néant), de Jean-Paul Sartre, essa fase teve alguns momentos capitais como, em 1945, a Fenomenologia da percepção (Phénoménologie de la perception), de Maurice Merleau-Ponty, e a tradução, acompanhada de comentários, das Idéias (Ideen), de Edmund Husserl, realizada por Paul Ricoeur e publicada em 1950.

A referência à fase francesa do movimento fenomenológico, no período de 1943-1953, indica a adesão aos critérios de divisão propostos por Herbert Spiegelberg em sua clássica obra $O$ movimento fenomenológico. Uma introdução histónica (The phenomenological movement. a historical introduction), 1960, o qual distingue uma fase francesa da fase alemã primigênia.

$\mathrm{Na}$ Alemanha, a história do movimento fenomenológico pode ser estudada tomando como ponto de partida a divisão em cinco círculos, consoante G. Funke. ${ }^{1}$ Pois no círculo de Munique, ao lado de A. Reinach, A. Pfänder. D. von Hildebrand e H. Spiegelberg, encontrava-se Moritz Geiger (1880-1937). Com base no testemunho de Spiegelberg, sabemos que havia, em Munique, um grande interesse pelos problemas do valor e da estética. Geiger também é citado entre os integrantes do

Professor da Universidade Federal do Paraná.

Ver FUNKE, G. Phänomenologie - Metaphysik oder Methode? Bonn: H. Bouvier u. Co. Verlag, 1966. P. 82-83. 
círculo de Göttingen. Ora, em Göttingen estava o polonês Roman Ingarden (18931970). Geiger e Ingarden são tidos como os iniciadores da estética fenomenológica.

Após ter travado, no século XIX, as célebres polêmicas entre os adeptos de uma Estética do alto (idealismo metafísico) e de uma Estética de baixo (empirismo psicológico), a estética alemã, no início do século XX, parecia ter ingressado num período de tal fecundidade que, diante do número de publicações, Victor Basch, em 1912, observou que se tratava de algo presque terrifiant. ${ }^{2}$ Foi a época da Estética (Ästhetik), de Th. Lipps (1903-1906), do Sistema da Estética (System der Ästhetik), de J. Volkelt, e da fundação, em 1906, por Max Dessoir, da Zeitschrift für Ästhetik und allgemeine Kunstwissenschaft, que permitia abranger toda a produção estética germânica.

Max Dessoir e Emil Utitz estiveram à frente do movimento Ästhetik und allgemeine Kunstwissenschaft, o qual propunha a distinção entre uma ciência geral da arte (Kunstwissenschaft) - voltada ao estudo da arte, em seus múltiplos aspectos - e a estética (Ästhetik) - que se ocupava do belo e da experiência estética.

Os estetas alemães costumavam pedir emprestado métodos de ciências afins como, por exemplo, da psicologia, sociologia e antropologia. Por isso não é de estranhar que alguns discípulos de Husserl tenham cogitado em aplicar o método fenomenológico à estética. Há historiadores que recuam até 1908, com o início da publicação de um longo estudo de Waldemar Conrad $O$ objeto estético. Um estudo fenomenológico (Der ästhetische Gegenstand. Eine phänomenologische Studie), com inequívoca influência husserliana, para assinalar a data do primeiro texto de índole fenomenológica no contexto da estética.Como, porém, o estudo de Conrad não obteve a repercussão que merecia, foi preciso esperar por Geiger e Ingarden, alguns anos mais tarde, para o nascer da estética fenomenológica propriamente dita.

Moritz Geiger, ao assumir a orientação realista da fenomenologia, procurou manter a experiência estética fora do raio de ação do sentimentalismo. No estudo Contribuições para a fenomenologia do prazer estético (Beiträge zur Phänomenologie des ästhetischen Genusses), publicado no primeiro volume do anuánio de Husserl (1913), Geiger ocupou-se da experiência do prazer estético. Em 1924, na comunicação Estética fenomenológica (Phänomenologische Ästhetik), ele conseguiu superar a propensão pela linha subjetiva ao tratar da natureza da obra de arte, alcançando o equilíbrio entre o subjetivo e o objetivo que haveria de caracterizar a estética fenomenológica.

Em 1927, Ingarden começou a redigir suas reflexões sobre a literatura com o propósito de exceder a dicotomia que distinguira a Ästhetik und allgemeine Kunstwissenschaft. Como ele mesmo revelou, em 1969, numa comunicação à Universidade de Amsterdam:

BASCH, V. Les grands courants de l'esthétique allemande contemporaine. Revue philosophique, 37 , p. 26, 1912. 
"Eu pensei que fosse um erro lançar uma contra a outra as duas linhas de pesquisa: a) a pesquisa geral sobre a obra de arte; e b) a experiência estética, seja no sentido de uma experiência criadora do autor, seja no sentido de uma experiência receptiva do leitor ou expectador."

Ao aderir à fenomenologia, durante a longa convivência com Husserl, Ingarden convenceu-se de que era possivel abarcar em sua investigação tanto o subjetivo, quanto o objetivo. Em 1931, lançou $A$ obra de arte literána (Das literanische Kunstwerk), ${ }^{4}$ obra indipensável para todos aqueles que se dedicam à estética da literatura.

Na coletânea $A$ estética $e$ as ciências da arte, Mikel Dufrenne aborda a arte sob dois prismas: 0 eidético e o transcendental. Ambos correspondem à natureza dual da fenomenologia. Conrad, Geiger e Ingarden são os representantes da abordagem sob o ângulo eidético. Quanto ao transcendental, Martin Heidegger (poesia), Jean-Paul Sartre (literatura) e Maurice Merleau-Ponty (pintura) são os escolhidos, pois "nos convidam a refletir sobre a experiência - singular e insubstituivel que a arte nos permite". 5 A esses três nomes cumpre acrescentar o do próprio Dufrenne.

No "caminho do pensamento" de Martin Heidegger (1889-1976) é possivel identificar reflexões que pertencem à estética. É o ensaio A Origem da Obra de Arte (Der Ursprung des Kunstwerkes), são os comentários sobre poetas, são os escritos acerca da linguagem. À primeira vista, Dufrenne parece refratário a toda e qualquer influência heideggeriana. Ora atraído, ora repelido pelo pensamento do autor de Ser e Tempo, o esteta francês chegou a confessar sua ambição de substituir a noção "generosa e fugidia" do ser heideggeriano pela idéia de Natureza ou, em outras palavras, substituir uma filosofia do ser por uma filosofia ou ontologia da Natureza. Jean-Paul Sartre (1905-1980) fez várias incursões nos domínios da estética como, por exemplo, a conclusão de $O$ imagináno (L'imaginaire) e o ensaio Que é a literatura? (Qu'est-ce que la littérature?), referência obrigatória para as discussões sobre literatura engajada e, por extensão, arte e política. Maurice Merleau-Ponty (1908-1961), além da dimensão estética de sua obra, tão valorizada hoje em dia, é o autor dos ensaios $O$ olho e o espínito ( $L$ 'oeuil et l'esprit) e $A$ dúvida de Cézanne (Le doute de Cézanne), em que medita com grande carinho sobre a pintura e sobre aqueles pintores que, como Cézanne, são capazes de "pensar com a pintura". Dufrenne filiou-se à versão francesa da fenomenologia, sob a liderança de Sartre e Merleau-Ponty, e o estudo do seu itinerário estético-filosófico revela forte influência de ambos os autores.

No dia 6 de junho de 1953, Mikel Dufrenne apresentava a Phénoménologie de l'expérience esthétique como tese principal para o doutorado na Sorbonne. E, no

INGARDEN, R. Phenomenological aesthetics: an attempt at defining its range. The Joumal of Aesthetics and Art Criticism, v. 33, n. 3, p. 259, 1975.

4 INGARDEN, R. A obra de arte literária. 2. ed. Trad. A. Beau, M. C. Puga, J. Barrento. Lisboa: Fundação C. Gulbenkian, 1979.

5 DUFRENNE, M. (org.) A estética e as ciências da arte. Trad. A. Bravo. Lisboa: Bertrand, 1982. v. 1, p. 108. 
mesmo ano, a editora Presses Universitaires de France publicava a primeira edição de sua tese. Logo no início do livro, o autor esclarece:

"Ver-se-á que nós não nos sentimos obrigado a seguir Husserl literalmente. Nós entendemos fenomenologia no sentido em que Sartre e Merleau-Ponty aclimataram esse termo na França: descrição que visa a uma essência, ela mesma definida como significação imanente ao fenômeno e dada com ele."

Dufrenne adota o método fenomenológico sem, contudo, subscrever à doutrina husserliana em todos os seus desdobramentos. Por maior que seja o tributo devido ao mestre, ele jamais aceitará o idealismo transcendental. $\mathrm{E}$ se, por um lado, a referência a Sartre e a Merleau-Ponty tem o mérito de nos situar na esteira da versão francesa da fenomenologia, por outro lado, ela suscita algumas interrogações no espírito do leitor. Sartre e Merleau-Ponty foram, de fato, responsáveis pela aclimação da fenomenologia na França. A Sartre coube a iniciativa da transposição bem como o empenho em fundir a fenomenologia com o existencialismo. Merleau-Ponty evitou que a fenomenologia se tornasse um simples meio para 0 existencialismo e soube dar prestígio acadêmico ao movimento fundado por Husserl. Mas entre Sartre e Merleau-Ponty há pontos em comum e pontos de divergência. Divergências até mesmo no que tange à noção de fenomenologia. Neste sentido, o estudo da obra de Dufrenne oferece subsídios para uma reavaliação da fase francesa da fenomenologia.

A Phénoménologie foi editada em dois tomos. O primeiro trata do objeto estético e subdivide-se, por sua vez, em duas partes: fenomenologia do objeto estético e análise da obra de arte. O segundo tomo compreende a fenomenologia da percepção estética e a crítica da experiência estética. Se, porém, levarmos em conta o escopo do livro e sua estrutura intema, poderemos dividi-lo da seguinte maneira:

1. descrição fenomenológica;

2. análise transcendental;

3. significação ontológica da experiência estética.

Essa divisão oferece a vantagem de não só englobar as três partes em que a obra está estruturada, como também servir de fio condutor para o estudo de um itinerário que se prolonga muito além das páginas do livro publicado em 1953.

A Phénoménologie está circunscrita à experiência do expectador. Mas existe uma intercomunicação entre a experiência do expectador e a experiência do artista. Não é possivel descrever a experiência do expectador sem ter presente, ao menos implicitamente, a experiência do artista. Trata-se, porém, do artista que a obra de arte revela. É na obra, portanto, que se realiza o encontro entre expectador e artista.

Qual será o ponto de partida da descrição da experiência estética: a percepção ou o objeto estético? Para não correr o risco de subordinar o objeto à percepção, Dufrenne elege o objeto estético. Sem negar a possibilidade de experiências

6 DUFRENNE, M. Phénoménologie de l'expérience esthétique. Paris: PUF, 1967. p. 4, note 1. 
estéticas perante a natureza, ele limita a noção de objeto estético à obra de arte e, conseqüentemente, a experiência estética às experiências vividas diante de obras de arte. Objeto estético é a obra de arte percebida como obra de arte. Ou: a obra de arte percebida esteticamente. A pergunta que se ouve tantas vezes: o que é uma obra de arte? - Dufrenne, embora cônscio da gravidade do problema, apela para o critério da tradição: "É obra de arte tudo aquilo que é reconhecido como tal e proposto como tal ao nosso entendimento"?

A descrição do objeto estético desenvolve-se em três planos noemáticos: 0 sensível, o objeto representado e o mundo expresso. O fato de partir da obra de arte percebida esteticamente facilita a compreensão do porquê da escolha do sensivel como primeiro momento noemático. Não se trata de um sensivel bruto. Um sentido é imanente ao sensivel. Competirá à forma tanto a organização do sensível, quanto a manifestação da plenitude do sentido ordenada à percepção. No concernente ao segundo momento, ou seja, o objeto representado, Dufrenne limita-se às artes figurativas para sublinhar que o objeto representado não é essencial à obra de arte. Insurge-se contra aqueles que, na percepção, se apegam ao objeto representado tomando-o como critério de apreciação ou de avaliação. A finalidade da arte não reside na representação. Se procurarmos o essencial, será necessário ir ao mundo expresso, o qual é estabelecido como terceiro momento noemático. A descrição culmina na expressão, certamente um dos pontos fortes da estética de Dufrenne.

Ao designar os três planos noemáticos, Dufrenne distingue entre o objeto representado e o mundo expresso. Isto quer dizer que ele nega à representação a possibilidade de abertura de um mundo. Vejamos o exemplo de Cézanne:

"Cézanne ao pintar a montanha Sainte-Victoire não nos dá uma lição de geografia; mas o que ela expressa? A potência de uma natureza mineral? A nudez de um mundo que a luz restitui ao elementar? A cumplicidade secreta que o inerte encontra numa alma que se despoja? Não podemos dizer: somente Cézanne o diz, numa linguagem intraduzível que apenas podemos escutar. Mas é certo que nos convida a viver com ele certa experiência do mundo."

E sobre o mundo de Cézanne: "é a Provença, uma terra ossuda e ardente, e personagens que têm a opacidade imóvel desta terra". "

No plano da representação, isto significa que o expectador não pode recorrer à semelhança ou exatidão como critério de julgamento das telas de Cézanne que representam a montanha Sainte-Victoire. No plano da expressão, o expectador deve estar pronto a viver, pelo sentimento, "uma certa experiência do mundo" ou a penetrar no mundo de Cézanne.

Ao elaborar a noção de mundo do objeto estético, Dufrenne, fiel à lição aristotélica, estabelece, em primeiro lugar, o princípio superior da unidade. Unidade essa que inclui a unidade de atmosfera que respiramos, por exemplo, nos filmes

Tbid., p. 16-17.

DUFRENNE, M. Estética e filosofia. Trad. R. Figurelli. São Paulo: Perspectiva, 1972. p. 262.

DUFRENNE, Phénoménologie, p. 248. 
de Fellini ou nos romances de Flaubert. Depois, a visão do mundo: "Essa Weltanschauung não é uma doutrina, ela é antes essa metafísica viva em todo homem, essa maneira de estar-no-mundo que se revela num comportamento". ${ }^{10}$ A superioridade do artista, em relação ao homem comum, é que sua expressão encontra unidade no objeto estético e se alça às dimensões de um mundo. Por último, a profundidade do objeto estético, como o demonstra a História da Arte. Observe-se ainda que o mundo do objeto estético pode ser designado pelo nome do artista: 0 mundo de Cézanne, de Matisse, de Van Gogh. E Dufrenne chega mesmo a cunhar certas fórmulas destinadas a expressar o matiz do sentimento próprio do mundo do artista como, por exemplo, o patético de Beethoven, a serenidade de Matisse, a gravidade de Rembrandt.

Aos três aspectos noemáticos - sensível, objeto representado e mundo expresso - correspondem aproximadamente a presença, a representação e a reflexão. Esses três aspectos noéticos são tomados por empréstimo de uma teoria geral da percepção, mas - por meio de um paralelismo entre o noético e o noemático o autor se esforça em pôr em relevo o que especifica a percepção estética.

Ao sensivel corresponde o plano da presença. Se, por um lado, falamos de "apoteose" ou "magia" do sensível, por outro, é necessário um sujeito capaz de perceber essa apoteose ou essa magia. A percepção, visualizada por Dufrenne como uma tarefa, é, em seu sentido pleno, "apreensão de uma significação". ${ }^{11} \mathrm{O}$ primeiro momento - a presença - é caracterizado como o plano existencial da percepção, onde o sujeito é capaz de apreender a significação do objeto por uma experiência vivida e não por um ato de decifração. Ora, isso só é possivel se houver presença no mundo, a qual define o sujeito como ser-no-mundo.

No plano da representação, Dufrenne estuda, num primeiro momento, o papel desempenhado pela imaginação na percepção para, num segundo momento, tratar da imaginação na percepção estética. Enraizada no corpo, cabe a ela a ligação entre o espírito e o corpo. Na esteira de Heidegger, distingue entre o aspecto transcendental e o aspecto empírico da imaginação. Essa distinção é instituída a fim de realçar a unidade dos dois aspectos. Eles são distintos, mas um completa 0 outro. Se compete à imaginação transcendental abrir um campo onde o dado possa aparecer, é à imaginação empírica que incumbe o "povoamento" deste campo. A imaginação é raiz do espaço e do tempo. Ora, pelo aparecimento do espaço e do tempo, advém a representação. É por isso que Dufrenne situa a imaginação no limiar da representação. $O$ advento da representação não deve ser visto como uma ruptura no processo da percepção. Há continuidade entre presença e representação.

No respeitante à relação entre imaginação e percepção, Dufrenne opõe-se à tese de Sartre, em L'imaginaire, segundo o qual há uma oposição irredutivel entre as duas faculdades. Todo o esforço do esteta francês visa a situar as duas atitudes da consciência em termos de "cooperação". A imaginação está sempre vinculada

$10 \quad$ Ibid., p. 234.

11 Ibid., p. 421. 
à percepção. Enquanto Sartre vê a relação entre as duas sob o ângulo da oposição entre real e irreal, Dufrenne sublinha que a imaginação está voltada para 0 real. Quanto ao papel da imaginação na percepção estética, o autor parece muito preocupado em coibir os excessos da imaginação. Mas a cautela, adotada na Phénoménologie, foi-se atenuando no decurso dos anos até chegar a uma posição diferente que, no meu entendimento, faz justiça à imaginação na experiência estética. Basta conferir O poético (Le poétique), de 1963, e O inventário dos a priori. Busca do onginário (L'inventaire des a prioni. Recherche de l'originaire), de 1981.

No terceiro momento noético, Dufrenne examina a função do intelecto, sua relação com a imaginação, os diferentes tipos de reflexão, a noção de profundidade para, então, se elevar ao sentimento como ápice da percepção estética. Intelecto e imaginação, na percepção estética, estão sob o signo da ambigüidade. Ambigüidade, aqui, na acepção proposta por Merleau-Ponty no Elogio da filosofia (Éloge de la philosophie) e tão do agrado de Dufrenne: "o filósofo reconhece-se em ter inseparavelmente o gosto da evidência e o sentido da ambigüidade". ${ }^{12}$ Se é verdade que $o$ intelecto exerce um controle sobre a imaginação, não esqueçamos que 0 intelecto nada pode sem ela.

Observa-se uma simetria entre a descrição do objeto estético, que culmina na expressão (mundo expresso) e a descrição da percepção, que atinge a culminância no sentimento. É pelo sentimento que o expectador é capaz de ler a expressão do objeto estético. O reconhecimento da função do intelecto na percepção não pode incidir no erro de transformar a experiência estética em solução de problemas ou decifração de enigmas. Da mesma forma, a preeminência do sentimento não deve levar ao erro de tudo sacrificar em prol do sentimento. Na atitude estética há uma espécie de oscilação entre a postura crítica e a sentimental.

Concluída a descrição da experiência estética, Dufrenne submete-a à análise transcendental. Tomando como modelo os a priori kantianos da sensibilidade e do entendimento, introduz a noção de a priori da afetividade para designar as condições sob as quais a dimensão do mundo do objeto estético pode ser apreendida pelo sentimento do expectador. Tal é o intento da Quarta Parte da Phénoménologie, intitulada "Crítica da experiência estética". O desiderato do autor é pensar o a priori mais como sentido imediato do objeto conhecido do que como condição lógica do conhecimento. O a priori, anterior à experiência, reside no sujeito como saber virtual. Em oposição a Kant, propõe um desdobramento do a priori no sujeito e no objeto, isto é, conhecimento no sujeito e estrutura imanente no objeto. A Quarta Parte da Phénoménologie foi apenas o início de uma reflexão que haveria de se prolongar em $A$ noção do a priori (La notion d'a prioni), de 1959, para atingir o seu coroamento, em 1981, com L'inventaire des a priori.

No último capítulo da Phénoménologie, o leitor percebe um momento de hesitação. Primeiro, a tentativa de apreender a significação ontológica da experiência estética. Depois, a retomada da distinção entre exegese antropológica e exegese

12 DUFRENNE, M. Philosophie de l'homme et philosophie de la nature. Les études philosophiques, Nouvelle Série, 25, p. 307, 1970. 
ontológica. Se a revelação oferecida pela obra de arte pertence exclusivamente à iniciativa do artista, estamos diante de uma exegese antropológica. A ontológica confere a revelação ao próprio ser e considera o artista como ocasião ou instrumento de revelação. Embora o cerco ao ontológico se aperte, o livro termina com o autor confessando sua dúvida acerca da necessidade da crítica se voltar ou não para a ontologia.

Alguns anos mais tarde, na Terceira Parte de La notion d'a priori, após ter estabelecido a afinidade entre o homem e o mundo, Dufrenne efetua 0 salto do transcendental ao ontológico. Ele apresenta a idéia de um ser anterior ao a priori: é o a priori do a priori. Com isso se consuma a apreensão da significação ontológica da experiência estética. A busca do a priori do a priori leva-o a uma filosofia da natureza em $O$ Poético, onde a Natureza naturante se impõe como fonte de todo a prion.

Como se delineia, na obra de Dufrenne, a noção de fenomenologia? Desde 1953, ele passou a expor, em conferências e escritos, o que entendia por fenomenologia. Visto que, aos poucos, Dufrenne foi assumindo o posto de representante por excelência da estética fenomenológica, não é para estranhar que sua idéia de fenomenologia esteja vinculada à estética. No que tange à natureza da estética, ele é categórico: "a estética só pode se realizar no interior de uma filosofia". Embora não mais se possa jogar sobre a estética a pecha da normatividade, isso não deve ser visto como perda de rigor. ${ }^{14}$ Ela conserva o seu caráter reflexivo e, por isso mesmo, é filosofia.

No texto "O que é a estética", ele começa com uma definição provisónia: “a estética é uma reflexão sobre as artes". ${ }^{15}$ É como reflexão sobre as artes que a estética se insere nos discursos dos historiadores, dos críticos, dos artistas, dos políticos. "O objeto que ela se atribui é a elucidação do que se faz e do que se busca em certas experiências: em certa experiência do mundo, mas sobretudo na experiência daquilo que nossa cultura chama de arte". ${ }^{16}$ A estética é meditação, elucidação ou reflexão sobre a experiência em que se revela o objeto estético. Ora, o conceito de objeto estético abarca tanto as obras de arte, quanto a natureza. A experiência que o homem faz da arte e da natureza é denominada experiência estética. Ainda que Dufrenne tenha concentrado sua atenção na experiência vivida diante de obras de arte, isso não significa menosprezo pela experiência estética da natureza. Basta lembrar o artigo "A Experiência Estética da Natureza"."

13 DUFRENNE, Estética e filosofia, p. 22.

${ }^{14}$ A distinção entre estética e poética - proposta pelo grupo de estetas da Universidade de Turim, com L. Pareyson à frente - reafirma o caráter filosófico e especulativo da estética, reservando à poética o caráter programático, operativo e normativo. Ver PAREYSON, L. Os problemas da estética. Trad. M. H. N. Garcez. São Paulo: Martins Fontes, 1984. p. 24-27.

15 DUFRENNE, M. O que é a estética. Trad. M. G. Bordini. Correio do Povo, Caderno de Sábado, 28 nov. 1970, p. 4.

18 DUFRENNE, M. Phénoménologie et esthétique. In: TYMIENIECKA, A.-T. (éd.). Analecta husserliana, 1976, v. 5, p. 241.

17 Ver DUFRENNE, M. Estética e filosofia, p. 60-77. 
A estética fenomenológica deve estribar-se no sujeito, mas sem se enredar nas malhas do idealismo. A análise da experiência é intencional: "Uma estética inspirada pela fenomenologia não poderia renunciar a tomar em consideração o objeto: em termos husserlianos, a análise da experiência deve ser noéticonoemática". ${ }^{18}$ Sob esse aspecto, a Phénoménologie, mesmo restrita à experiência do expectador, é exemplo de uma análise noético-noemática da experiência estética.

Dufrenne é tributário de Merleau-Ponty ao descrever a percepção estética. A percepção é o começo absoluto, a origem da consciência, a emergência do sentido. Para ele, a percepção estética é a percepção mais acabada e feliz. A percepção atinge seus momentos mais fortes e intensos na experiência estética.

A idéia heideggeriana do homem como ser-no-mundo é recebida de braços abertos por Dufrenne, porque a fenomenologia não cessa de nos instruir acerca de nossa presença no mundo. É na experiência estética que se manifesta a relação mais profunda do homem com o mundo. A percepção estética reconduz o homem ao originário. Ora, l'originaire, em Dufrenne, se identifica com a Natureza. Tudo converge para uma ontologia ou filosofia da Natureza.

A estética fenomenológica não invalida a palavra de ordem de Husserl: o retorno às próprias coisas. "Interrogar-se sobre uma arte, um gênero ou uma categoria estética não é se desviar das obras: a essência só pode ser apreendida sobre 0 objeto por ela habitado e que ela torna inteligivel". ${ }^{19}$

Num artigo de 1954, intitulado "Intencionalidade e Estética", Dufrenne procurou demonstrar que a experiência estética do expectador pode ser evocada para clarificar a noção de intencionalidade. $O$ artigo situa-se no prolongamento de certos temas da Phénoménologie. De fato, retomando o estatuto do objeto estéti$\mathrm{co}$, o autor visualiza a possibilidade de aclarar o liame forjado pela intencionalidade entre o objeto e o sujeito.

Por fim, a percepção estética impõe-se como um campo privilegiado para a prática da redução: " $\mathrm{E}$ ousariamos dizer que a experiência estética realiza a redução fenomenológica no instante em que é pura" ${ }^{20}$ Mas há certas condições a serem observadas: a crença no mundo deve ser suspensa e todo interesse prático ou intelectual deve ser afastado. A percepção estética opera a neutralização - seja do irreal, seja do real - e o único mundo que pode estar presente ao sujeito é o mundo do objeto estético.

Dentre as muitas contribuições da fenomenologia, saliento a abertura ao mundo e a lição inestimável que nos ensina a olhar para o mundo com outros olhos. É nessa perspectiva que Mikel Dufrenne vê na estética fenomenológica um método adequado para abordar a arte contemporânea e descortinar ao homem, por meio da arte, novos horizontes sobre um mundo totalmente diferente. 


\section{Referências bibliográficas}

BASCH, V. Les grands courants de l'esthétique allemande contemporaine. Revue philosophique, 37, $\mathrm{p}$. 22-43, 1912.

DUFRENNE, M. (org.) A estética e as ciências da arte. Trad. A. Bravo. Lisboa: Bertrand, 1982. v. 1. Estética e filosofia. Trad. R. Figurelli. São Paulo: Perspectiva, 1972.

. O que é a estética. Trad. M.G. Bordini. Correio do Povo, Caderno de Sábado, 28 nov.; 1970, p. 4-5.

Phénoménologie de l'expérience esthétique. 2. ed. Paris: PUF, 1967.

Phénoménologie et esthétique. In: TYMIENIECKA, A.-T. (éd.) Analecta husserliana. 1976, v. 5, p. 241-246, 1976.

. Phénoménologie et ontologie de l'art. In: Les sciences humaines et l'oeuvre d'art. Bruxelles: La Connaissance, 1969. p. 143-160.

Philosophie de l'homme et philosophie de la Nature. Les Etudes Philosophiques, Nouvelle Série, 25, p. 307-317, 1970.

FUNKE, G. Phänomenologie - Metaphysik oder Methode? Bonn: H. Bouvier u. Co. Verlag, 1966.

INGARDEN, R. A obra de arte literánia. Trad. A. Beau, M. C. Puga, J. Barrento. Lisboa: Fundação C. Gulbenkian, 1979.

- Phenomenological aesthetics: an attempt at defining its range. The Joumal of Aesthetics and Art Criticism, v. 33, n. 3, p. 257-269, 1975.

PAREYSON. L. Os problemas da estética. Trad. M. H. N. Garcez. São Paulo: Martins Fontes, 1984. p. 24-27. 